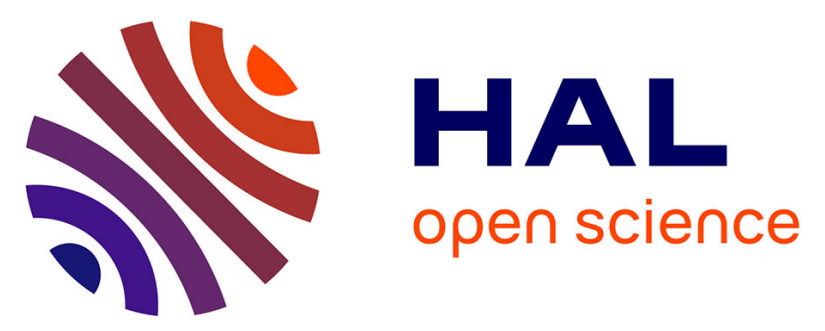

\title{
A New Experimental Method to Determine the Evaporation Coefficient of Trichloroethylene (TCE) in an Arid Soil
}

Samuel Ouoba, Tizane Daho, Fabien Cherblanc, Jean Koulidiati, Jean-Claude Benet

\section{To cite this version:}

Samuel Ouoba, Tizane Daho, Fabien Cherblanc, Jean Koulidiati, Jean-Claude Benet. A New Experimental Method to Determine the Evaporation Coefficient of Trichloroethylene (TCE) in an Arid Soil. Transport in Porous Media, 2015, 106, pp.339-353. 10.1007/s11242-014-0404-6 . hal-01121707

\section{HAL Id: hal-01121707 \\ https://hal.science/hal-01121707}

Submitted on 2 Mar 2015

HAL is a multi-disciplinary open access archive for the deposit and dissemination of scientific research documents, whether they are published or not. The documents may come from teaching and research institutions in France or abroad, or from public or private research centers.
L'archive ouverte pluridisciplinaire $\mathbf{H A L}$, est destinée au dépôt et à la diffusion de documents scientifiques de niveau recherche, publiés ou non, émanant des établissements d'enseignement et de recherche français ou étrangers, des laboratoires publics ou privés. 


\title{
A New Experimental Method to Determine the Evaporation Coefficient of Trichloroethylene (TCE) in an arid soil.
}

\author{
Samuel Ouoba $^{\bullet, 1}$, Tizane Daho ${ }^{1}$, Fabien Cherblanc ${ }^{2}$, Jean Koulidiati ${ }^{1}$, Jean-Claude Bénet ${ }^{2}$ \\ ${ }^{1}$ Laboratoire de Physique et de Chimie de l'Environnement, Université de Ouagadougou, UFR-SEA, O3 \\ BP 7021 Ouaga 03, Burkina Faso \\ ${ }^{2}$ Laboratoire de Mécanique et Génie Civil, UMR CNRS 5508, Université Montpellier 2, Cc 048, Place Eugène \\ Bataillon, 34000 Montpellier, France
}

Transport in Porous Media

\begin{abstract}
This paper presents a new method to determine the evaporation coefficient of trichloroethylene using a new experimental device called "activity-meter". This device and the associated method have been developed in the Laboratory of Mechanical Engineering of the University of Montpellier 2 (France). The influence of diffusion on the vapor pressure of trichloroethylene and the influence of temperature at the liquid-gas interface were first determined. The results show that diffusion phenomena have no influence on the vapor pressure of trichloroethylene beyond 400 seconds of experimental time and the temperature is almost constant during experiments. Thus, in order to take into account the effects that are only due to the variation of partial pressure of trichloroethylene at the liquid-gas interface, the time interval used is between 400 seconds and the time required to reach equilibrium. The influence of pressure and temperature on the evaporation coefficient of pure trichloroethylene in an arid soil was then highlighted. The results show that the evaporation coefficient of trichloroethylene decreases with total vapor pressure but increases with temperature. A comparative study on evaporation coefficients conducted on water, heptane and trichloroethylene shows that our results are in good agreement with results on volatility.
\end{abstract}

Keywords: Trichloroethylene, evaporation coefficient, pressure, temperature, activity-meter.

\section{Nomenclature}

$C_{\mathrm{p}} \quad$ Constant pressure specific heat

$D_{\text {va }} \quad$ Diffusion coefficient of TCE vapor in air

$\mathrm{J} \mathrm{kg}^{-1} \mathrm{~K}^{-1}$ $\mathrm{m}^{2} \mathrm{~s}^{-1}$

$h_{1} \quad$ Length of the sample

$\mathrm{m}$

$h_{2} \quad$ Diffusion length

$J \quad$ Evaporation flux

$L \quad$ Evaporation coefficient of TCE

$L_{\mathrm{v}} \quad$ Latent heat of vaporization

$M_{\mathrm{a}} \quad$ Molar weight of air

$m_{\mathrm{a}} \quad$ Mass of air

$M_{\mathrm{v}} \quad$ Molar weight of vapor

$m_{\mathrm{v}}^{1} \quad$ Mass of the vapor in compartment 1

$\mathrm{kg} \mathrm{m}^{-3} \mathrm{~s}^{-1}$

$\mathrm{kg} \mathrm{K} \mathrm{s} \mathrm{m}^{-5}$

$\mathrm{J} \mathrm{kg}^{-1}$

$\mathrm{kg} \mathrm{mol}^{-1}$

$m_{\mathrm{v}}^{2} \quad$ Mass of the vapor in compartment 2

$\mathrm{kg} \mathrm{mol}^{-1}$

$n_{\mathrm{a}} \quad$ Mole number of dry air

$\mathrm{kg}$

mol

$\begin{array}{ll}P_{\mathrm{a}} \quad \text { Air pressure } & \mathrm{Pa}\end{array}$

•Corresponding author, LPCE, Université de Ouagadougou, 03 BP 7021 Ouaga 03, Burkina Faso.

Tel.: (+226) 70-13-03-01 / (+226) 76-67-15-57

E-mail address: samuel_ouoba1@yahoo.fr (Samuel Ouoba) 
$P_{\text {Heq }} \quad$ Equilibrium partial pressure of heptane $\quad P a$

$\begin{array}{lll}P_{\mathrm{g}} \quad \text { Total pressure of gas } & \mathrm{Pa}\end{array}$

$P_{\text {Taver }}$ Average partial vapor pressure of TCE measured by the pressure sensor $\quad \mathrm{Pa}$

$\begin{array}{lll}P_{\text {Teq }} & \text { Equilibrium partial pressure of TCE } & \mathrm{Pa}\end{array}$

$\begin{array}{lll}P_{\text {Tsurf }} & \text { Simulated vapor pressure of TCE } & \mathrm{Pa}\end{array}$

$\begin{array}{lll}P_{\mathrm{v}} & \text { Vapor pressure } & \mathrm{Pa}\end{array}$

$\begin{array}{ll}P_{\text {veq }} \quad \text { Equilibrium vapor pressure } & \mathrm{Pa}\end{array}$

$\begin{array}{ll}P_{\text {vini }} \quad \text { Initial vapor pressure } & \mathrm{Pa}\end{array}$

$\begin{array}{ll}P_{\text {weq }} \quad \text { Equilibrium partial pressure of water } & \mathrm{Pa}\end{array}$

$R \quad$ Ideal gas constant $\quad \mathrm{J} \mathrm{K}^{-1} \mathrm{~mol}^{-1}$

$S \quad$ Surface of the sample

$T \quad$ Temperature of the system

$\mathrm{m}^{2}$
$\mathrm{~K}$

$\begin{array}{lll}T_{0} & \text { Initial temperature } & \mathrm{K}\end{array}$

$V \quad$ Total gas phase volume $\mathrm{m}^{3}$

$\begin{array}{lll}V_{0} & \text { Gas phase volume in the initial equilibrium position } & \mathrm{m}^{3}\end{array}$

$V_{1} \quad$ Volume of compartment $1 \quad \mathrm{~m}^{3}$

$\begin{array}{lll}\lambda & \text { Thermal conductivity } & \mathrm{W} \mathrm{K}^{-1} \mathrm{~m}^{-1}\end{array}$

$\phi_{\mathrm{g}} \quad$ Volume fraction of gas /

$\rho_{\mathrm{v}} \quad$ Apparent density of vapor $\quad \mathrm{kg} \mathrm{m}^{-3}$

$\begin{array}{lll}\rho_{\mathrm{v}}^{*} & \text { Real density of vapor } & \mathrm{kg} \mathrm{m}^{-3}\end{array}$

\section{Introduction}

Following their use in the environment, volatile organic compounds (VOCs) essentially have two phases i.e. liquid phase and gaseous phase (Auriault and Lewandowska 1997; Benker et al. 1998; Caron et al. 1998; Braida and Ong 2000; Hoeg et al. 2004). The passage between liquid phase and gas phase is called phase change. The monitoring of this phenomenon is an essential step in understanding the mechanisms of VOC dissipation for the remediation of environmental pollution (Lincoff and Gossett 1984; Staudinger and Roberts 1996; Altschuh et al., 1999; Dewulf et al. 1999; Staudinger and Roberts 2001; Brockbank et al., 2013; Kish et al., 2013). The results of the literature establish that most of the work conducted on the transfer of VOCs in soil, in particular, concerns either the saturated zone or the unsaturated zone without taking account of phase change, which represents a fundamental phenomenon in the latter zone (Rahli et al. 1996; Zhao et al. 2000; Gerolymatou et al. 2005; Tong et al. 2013).

As a process caused by thermodynamic non equilibrium, the evaporation coefficient reflects the relative volatility of a compound, and represents an essential property in the mechanisms of description and modelling the behaviour of VOCs in the environment (Hornbuckle et al., 1994; Schreitmüller and Ballschmiter, 1995). One of today's environmental problems concerns contaminant remediation technologies (Unger et al., 1996) and the fixing of compounds on soil particles. In soil, the properties of the compounds are modified by liquid/gas and liquid/solid interfaces (Lin et al., 1994). This change is even greater when the solid phase of soil is fractionated and contains organic matter (Steinberg, 1996).

Many authors have shown that in the saturated portion of the soil the free nature of liquid allows the application of classical laws of equilibrium between the liquid phase and the gaseous phase as they are known to date (Ficher et al. 1998; Liu et al. 2002; Stadler et al. 2012). In arid regions however, the low liquid contents are responsible for hygroscopic effects because the liquid is partially adsorbed on the solid phase, which strongly modifies its mechanical and thermodynamic properties (Chammari et al. 2003; Lozano et al. 2008). Indeed, recent studies have shown that hygroscopic effects modify the equilibrium laws of compounds at the liquid-gas interface and the mechanisms of water transfer (Lozano et al. 2008). This suggests that the same could apply for VOCs such as TCE, which can be found in an arid soil.

In order to numerically account for hygroscopic effects and better describe the mechanisms of transfer of a VOC during its transfer process in an arid soil, it is important to determine the evaporation coefficient of such compounds.

In this paper, we propose a new method to determine the evaporation coefficient of the NAPL phase of trichloroethylene (TCE) in an arid soil. The choice of an arid soil is justified by the fact that it contains a low amount of water strongly linked to the solid particles of the soil making its extraction very difficult. Thus, the evaporation phenomena of the TCE are weakly affected by the relative humidity of the soil and the amount of 
TCE able to dissolve in the water of the soil can be neglected. The aim of this work is to analyze the influence of certain parameters such as ambient temperature and pressure. To ensure that the pressure and temperature measured by the sensors are representative of the mean values in the sample, the influence of diffusion and thermal fluctuation were first studied. Indeed, the temperature and pressure measured by the sensors are used for the calculation of the evaporation coefficient.

\section{Materials and methods}

\subsection{Definition of the system}

The system studied in this work is a portion of soil containing a liquid phase (subscript $L$ ) which can be water (denoted by $w$ ), TCE (denoted by $T$ ) heptane (denoted by $\mathrm{H}$ ) and a gas phase (denoted by $g$ ) composed of air (denoted by $a$ ) and vapor. The following assumptions are admitted:

- A1: the solid phase is chemically inert and incompressible,

- A2:the temperature is uniform and constant,

- A3: the gas behaves like an ideal gas mixture,

- A4: the liquid phase of TCE is considered pure i.e. TCE is in a NAPL phase. This is also true for the other compounds,

- A5: there are no chemical reactions in liquid and gas phase. The only physic-chemical phenomenon to be taken into account is the liquid-gas phase change,

- A6: the porosity of the soil is assumed uniform, constant and equal to $43 \%$.

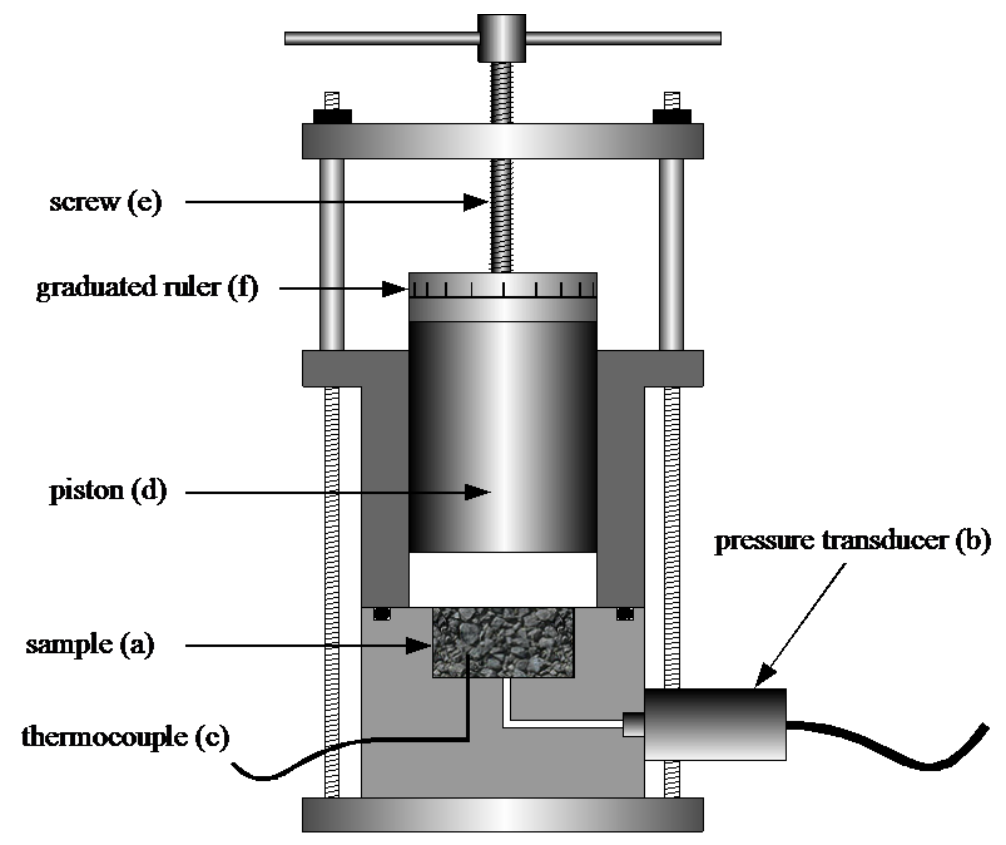

Fig. 1 Schematic diagram of the activity-meter

\subsection{Experimental device}

The experimental device is shown in Fig. 1. It was initially developed to measure water activity and was called an "activity-meter". This device and the associated method were validated using saturated salts (Ouoba et al. 2010a) and have been patented in United States (Bénet et al., 2012).

The sample (a) is placed against a pressure transducer (b) (Druck, PMP4030AB) and a temperature thermocouple (c) (type $\mathrm{K}$ ). This records the total pressure of the gas phase, $P_{\mathrm{g}}$, and its temperature, $T$, throughout the test. Data acquisition is performed through a National Instrument DAQ card and analyzed using LabView. A 
piston pump (d) is placed above the sample to impose a gas pressure below atmospheric pressure. The piston chamber volume is controlled by a screw system (e) with a graduated ruler (f). O-ring gaskets ensure perfect air tightness so that the system can be considered thermodynamically closed. The dimensional characteristics of the device are given by Ouoba et al. (2010b). The whole device is placed in a thermo-regulated bath to ensure a constant temperature. Because the device is made of stainless steel, its high thermal inertia leads to weak temperature variations and thermal equilibrium is experimentally observed.

\subsection{Method of determining TCE vapor pressure}

The gas phase enclosed in the experimental device is composed of dry air and vapor of the compound under investigation. In these conditions, vapor is in equilibrium with the liquid, meaning that its partial pressure is equal to its equilibrium vapor pressure, $P_{\text {Teq }}$. Starting from a state of equilibrium, the principle of the experiment consists in moving the piston up to a new position using the screw system and recording the evolution of the gasphase pressure and temperature. After a while, the gas pressure tends to a constant value that defines a new state of equilibrium.

This stage is repeated several times to provide a set of triplets $\left(T, \mathrm{~V}, P_{g}\right)$ where $T$ is the measured equilibrium temperature, $V$ is the volume imposed by the piston and $P_{\mathrm{g}}$ is the measured equilibrium total gas pressure.

Starting from atmospheric pressure, the gas pressure decreases at each piston displacement. This activates liquid evaporation observed through the slow rise of gas pressure until equilibrium. A slight temperature drop is experimentally observed resulting from liquid-gas interface cooling while evaporation occurs. Nevertheless, thermal regulation ensures a constant and homogeneous temperature inside the device.

Considering a sample at a given liquid content, $w_{\mathrm{L}}$, the unknown physical quantities are as follows:

- $\quad V_{0}$, the gas phase volume in the initial equilibrium position. This includes pore space inside the sample as well as the initial volume of the piston chamber and dead volumes in the pressure transducer.

- $\quad n_{\mathrm{a}}$, the mole number of the dry air inside the device that remains constant because it is a closed system.

- $\quad P_{\text {veq }}$, the equilibrium vapor pressure. Because the liquid amount evaporated during an experiment is negligible, the liquid content, $w_{\mathrm{L}}$, is considered to be constant. This assumption was experimentally checked by measuring the liquid content before and after each experiment. Therefore, the equilibrium vapor pressure can also be considered constant.

By assuming that dry air behaves as an ideal gas, the gas pressure can be written for each equilibrium stage as the sum of partial pressures of vapor and air:

$$
P_{\mathrm{g}}=P_{\mathrm{veq}}+P_{\mathrm{a}}=P_{\mathrm{veq}}+n_{\mathrm{a}} \frac{R T}{V_{0}+V}
$$

The ideal gas description is legitimate since air is far from its liquid-gas phase transition. To determine the 3 unknown quantities described above, $\left(V_{0}, n_{\mathrm{a}}, P_{\text {veq }}\right), 3$ equilibrium stages are sufficient: $\left(T, \mathrm{~V}, P_{\mathrm{g}}\right)$. However, to increase accuracy, 6-10 volume increments are performed. Thus, the 3 unknowns are identified using a nonlinear least-squares minimization procedure based on the standard Levenberg-Marquadt algorithm.

More details on the validation of this method are given in our previous works (Bénet et al. 2012; Ouoba et al. 2014; Ouoba et al. 2010a; Ouoba et al. 2010b)

\subsection{Method of determining the evaporation coefficient}

The principle of phase change law is based on the expression established by Bénet et al. (2009) and recently used by Ouedraogo et al. (2013). In the present study, the approach used is presented below: The sample composed by a mixture of soil and TCE and the air gap above it are shown in Fig. 2. The physical and chemical properties of TCE and the soil sample are respectively given in Tables 1 and 2.

A mass balance is performed in compartments 1 and 2 of respective volumes $V_{1}$ and $V_{2}$. Denoting by $m_{\mathrm{V}}^{1}$ and $m_{\mathrm{v}}^{2}$ the mass of the vapor, respectively in the two compartments, and taking into account the change in mass due to evaporation of the liquid phase, mass balance is given by Equation (2): 


$$
\frac{\mathrm{d} m_{\mathrm{V}}^{1}}{\mathrm{~d} t}+\frac{\mathrm{d} m_{\mathrm{V}}^{2}}{\mathrm{~d} t}=J V_{1}
$$

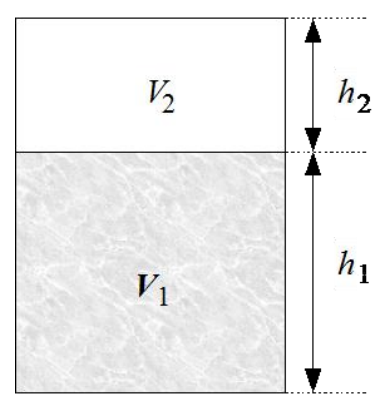

Fig. 2 Operating system to calculate the evaporation coefficient of TCE

Table 1 TCE physic-chemical properties at $30{ }^{\circ} \mathrm{C}$

\begin{tabular}{ccc} 
Equilibrium vapor pressure $/ \mathrm{Pa}$ & Henry's constant $/ \mathrm{Pa} \mathrm{m}^{3} \mathrm{~mol}^{-1}$ & $\begin{array}{c}\text { Solubility } \\
/ \mathrm{Mg} \mathrm{litre}^{-1}\end{array}$ \\
\hline 11912 & 1195.5 & 1310 \\
\hline
\end{tabular}

Table 2 Main characteristics of the soil

\begin{tabular}{cccc}
\hline $\begin{array}{c}\text { Particle size } \\
0-2 \mathrm{~mm}\end{array}$ & $\begin{array}{c}\text { Particle density } \\
2650 \mathrm{~kg}^{-3}\end{array}$ & $\begin{array}{c}\text { Apparent mass } \\
\text { density } 1500 \mathrm{~kg} \cdot{ }^{-3}\end{array}$ & $\begin{array}{c}\text { Porosity } \\
43 \%\end{array}$ \\
\hline $\begin{array}{c}\text { quartz content } \\
40 \%\end{array}$ & $\begin{array}{c}\text { calcite content } \\
45-50 \%\end{array}$ & $\begin{array}{c}\text { clay content } \\
10 \%\end{array}$ & \\
\hline organic matter & organic carbon & total N & $\mathrm{C} / \mathrm{N}$ \\
$0.28 \%$ & $0.16 \%$ & $0.10 \%$ & 16.83 \\
\hline$w_{\text {sat }}$ & $w_{r}$ & $K_{\text {sat }}$ & \\
$28.9 \%$ & $1 \%$ & $3.10^{-5} \mathrm{~m}_{\mathrm{s}} \mathrm{s}^{-1}$ & \\
\hline
\end{tabular}

$\mathrm{K}_{\text {sat }}=$ saturated permeability; $\mathrm{w}_{\text {sat }}=$ saturated water content; $\mathrm{w}_{\mathrm{r}}=$ residual water content .

Where $J$ is the evaporation flux of the compound

And

$$
V_{1}=S h_{1}
$$

Furthermore, the mass of vapor in compartment 1 is given by Equation (4):

$$
m_{\mathrm{v}}^{1}=\rho_{\mathrm{v}} S h_{1}=\phi_{\mathrm{g}} \frac{M_{\mathrm{v}}}{R T} P_{\mathrm{v}} S h_{1}
$$

And in compartment 2 by Equation (5):

$$
m_{\mathrm{v}}^{2}=\rho_{\mathrm{v}}^{*} S h_{2}=\frac{M_{\mathrm{v}}}{R T} P_{\mathrm{v}} S h_{2}
$$

Expressing the chemical potential, assuming that the temperature is constant and that there is no change in the composition of the liquid phase due to the action of chemical reactions which corresponds to the experimental conditions considered, the law of phase change of TCE is given by Bénet et al. (2009):

$$
J=-L \frac{R}{M_{\mathrm{v}}} \ln \left(\frac{P_{\mathrm{v}}}{P_{\mathrm{veq}}}\right)
$$

According to Equations (3), (4), (5) and (6), Equation (2) becomes: 


$$
\frac{M_{\mathrm{V}}}{R T} \frac{\mathrm{d} P_{\mathrm{V}}}{\mathrm{d} t}\left(\frac{h_{2}}{h_{1}}+\phi_{\mathrm{g}}\right)=-L \frac{R}{M_{\mathrm{v}}} \ln \left(\frac{P_{\mathrm{V}}}{P_{\mathrm{veq}}}\right)
$$

By integrating this relation between the time $t$ and the time that corresponds to the final equilibrium, $t_{\mathrm{eq}}$ Equation (7) becomes:

$$
\underbrace{\frac{\left(M_{\mathrm{v}}\right)^{2}}{R^{2} T}\left(\frac{h_{2}}{h_{1}}+\phi_{\mathrm{g}}\right)\left[P_{\mathrm{v}}\left(t_{\mathrm{eq}}\right)-P_{\mathrm{v}}(t)\right]}_{1^{\text {th }} \text { member }}=-L \underbrace{\int_{t}^{t e q} \ln \left(\frac{P_{\mathrm{v}}}{P_{\mathrm{veq}}}\right) \mathrm{d} t}_{2^{\text {th }} \text { member }}
$$

The integral of the second member of Equation (8) is determined using the experimental measurements of pressures. The curve representing the variation of the first member of Equation (8) as a function of the second member allows the determination of the evaporation coefficient.

\subsection{Basic equations to determine the influence of diffusion and thermal fluctuations.}

This section gives the basic equations to determine the influence of diffusion and thermal fluctuations on the calculation of the evaporation coefficient of TCE. According to Equation (7), it can be seen that the evaporation coefficient depends on the size $h_{1}$ of the sample and the diffusion length $h_{2}$. It can be assumed that the reequilibrium of vapor pressure in the system is not instantaneous and that thermal fluctuations due to evaporation of the liquid cause a significant drop in temperature. To check the sensitivity of evaporation coefficient to these two phenomena (diffusion and thermal fluctuations), a numerical model was used, which simulates the experimental profiles of partial vapor pressure of TCE in the gaseous phase located above the sample. Increments of the partial pressure produced by a rapid variation of volume were performed. This approach allowed us to highlight the effects of diffusion and thermal fluctuations on evaporation coefficient.

As reported previously, when the volume is increased there is disequilibrium between TCE liquid and gaseous phases, because vapor pressure drops below its equilibrium value. This leads to the evaporation of TCE on the surface of the liquid and produces a change in the total pressure of the gaseous phase. It can be assumed that at the time $\mathrm{t}=0$, the total pressure above the liquid is uniform between 0 and $h_{2}$. In this system, the pressure of the gaseous phase, denoted $P_{\mathrm{g}}(\mathrm{t})$, depends only on time and can be written:

$$
P_{\mathrm{g}}=f(t)
$$

The evolution of gaseous phase pressure is given by the pressure sensor. It is assumed that the temperature $T$ is uniform and constant. This hypothesis will be verified in the next sections. The objective is to calculate the distribution of vapor partial pressure above the liquid phase as a function of time between 0 and $h_{2}$ using the pressure of the gaseous phase $P_{\mathrm{g}}(\mathrm{t})$ measured by the pressure sensor.

\subsubsection{Mass transfer balance}

For mass transfer, it is assumed that the vapor pressure is a function of space and time.

\section{- Vapor balance:}

The major phenomenon which occurs during vapor transfer is diffusion as given by Equations (10) and (11):

$$
\frac{\partial P_{\mathrm{v}}}{\partial t}=-\nabla \cdot J
$$

Evaporation flux is given by Equation (11):

$$
J=-D_{\mathrm{va}} \nabla P_{\mathrm{v}}
$$

It is assumed that $P_{\mathrm{v}}$ has no influence on $D_{\mathrm{va}}$; this is supported by the negligible partial vapor pressure of TCE compared to the total pressure of the mixture air/vapor of TCE.

Then, Equation (10) can be written as follows: 


$$
\frac{\partial P_{\mathrm{v}}}{\partial t}=D_{\mathrm{va}} \Delta P_{\mathrm{v}}
$$

\section{- Boundary conditions}

For $z=0$, the vapor flux is obtained from the variation of $P_{\mathrm{v}}$. The mass $m_{\mathrm{v}}$ of the vapor contained in the cylinder is given by Equation (13):

$$
m_{\mathrm{v}}=\int_{0}^{h_{2}} \rho_{\mathrm{v}}^{*} S \mathrm{~d} z
$$

According to the ideal gas law, $\rho_{\mathrm{v}}^{*}$ is given by Equation (14):

$$
\rho_{\mathrm{v}}^{*}=\frac{M_{\mathrm{v}}}{R T} P_{\mathrm{v}}
$$

Vapor mass flow is then given by Equation (15):

$$
\frac{\mathrm{d} m_{\mathrm{v}}}{\mathrm{d} t}=\frac{\mathrm{d}}{\mathrm{d} t} \int_{0}^{h_{2}} \frac{M_{\mathrm{v}}}{R T} P_{\mathrm{v}} S \mathrm{~d} z
$$

By assuming that there is no dissolution of air in TCE, the total mass of air $m_{\mathrm{a}}$ contained in the cylinder is constant and it is given by Equation (16):

$$
\frac{\mathrm{d} m_{\mathrm{a}}}{\mathrm{d} t}=\frac{\mathrm{d}}{\mathrm{d} t} \int_{0}^{h_{2}} \frac{M_{\mathrm{a}}}{R T} P_{\mathrm{a}} S \mathrm{~d} z=0
$$

This means:

$$
\frac{\mathrm{d}}{\mathrm{d} t} \int_{0}^{h_{2}} P_{\mathrm{a}} \mathrm{d} z=0
$$

As $P_{\mathrm{g}}=P_{\mathrm{a}}+P_{\mathrm{v}}$ is independent of $z$, Equation (15) leads to Equation (18):

$$
\frac{\mathrm{d} m_{\mathrm{V}}}{\mathrm{d} t}=\frac{M_{\mathrm{v}}}{R T} S h_{2} \frac{\mathrm{d} P_{\mathrm{v}}}{\mathrm{d} t}(t)
$$

The vapor mass flow at $z=0$ is given by Equation (19)

$$
\frac{\mathrm{d} m_{\mathrm{V}}}{\mathrm{d} t}=J_{\mathrm{v} 0} S=-\left.D_{\mathrm{va}} \frac{M_{\mathrm{v}}}{R T}\left(\nabla P_{\mathrm{v}}\right)\right|_{z=0} S=\frac{M_{\mathrm{v}}}{R T} S h_{2} \frac{\mathrm{d} P_{\mathrm{g}}}{\mathrm{d} t}(t)
$$

So, boundary conditions at $z=0$ gives Equation (20):

$$
\left.\frac{D_{\mathrm{va}}}{h} \nabla P_{\mathrm{v}}\right|_{\mathrm{z}=0}=-\frac{\mathrm{d} P_{\mathrm{g}}}{\mathrm{d} t}(t)
$$

For $z=h_{2}$, there is no mass transfer of TCE; this leads to Equation (21):

$$
\left.\nabla P_{\mathrm{v}}\right|_{z=h_{2}}=0
$$

\section{- Initial conditions}

At the initial instant, the vapor pressure $P_{\text {vini }}$ is unknown but assumed to be independent of the variable $z$.

$$
\left.P_{\mathrm{v}}\right|_{t=0}=P_{\text {vini }}
$$

Partial pressure of TCE vapor tends to the equilibrium pressure with increasing time. This is given by Equation (23):

$$
P_{\mathrm{v}}(t) \rightarrow P_{\mathrm{veq}} \text { for } \mathrm{t} \rightarrow \infty
$$




\subsubsection{Heat transfer}

The temperature profiles near the surface were calculated by solving the equation of heat transfer in the liquid phase given by Equation (24):

$$
\frac{\partial T}{\partial t}=\frac{\lambda}{\rho_{\mathrm{v}} C_{\mathrm{p}}} \Delta T
$$

The boundary conditions on the lower surface of TCE are given by Equation (25):

$$
T(t)=T_{0}
$$

For a liquid layer with a thickness of $\mathrm{d} z$, the heat transfer balance is given by Equation (26):

$$
-\lambda \frac{\partial T}{\partial z}-\frac{M_{\mathrm{v}}}{R T} h_{2} L_{\mathrm{v}} \frac{\mathrm{d} P_{\mathrm{g}}}{\mathrm{d} t}=\rho_{\mathrm{v}} C_{\mathrm{p}} \mathrm{d} z \frac{\partial T}{\partial t}
$$

\section{Results and discussion}

\subsection{Influence of diffusion on the distribution of TCE vapor pressure}

The experimental data show that the time required to reach equilibrium is relatively long (about 10 minutes). Above $400 \mathrm{~s}$ of experimental time, the kinetics of the simulated vapor pressure of TCE $\left(P_{\text {Tsurf }}\right)$ and the average partial vapor pressure measured by the pressure sensor $\left(P_{\text {Taver }}\right)$ are almost the same $($ Fig. 3). This means that $P_{\text {Taver }}$ can be used as well as $P_{\text {Tsurf }}$, to calculate the evaporation coefficient. In addition, the 10 minutes necessary to reach equilibrium show that there is no instantaneous equilibrium at the liquid-gas interface.

Analysis of Fig. 4 shows that TCE vapor pressure is uniform along the diffusion length above $400 \mathrm{~s}$. This indicates that over this time, diffusion in the air is not decisive during the return to equilibrium. Therefore, the calculation of evaporation coefficient was performed for a time interval above $400 \mathrm{~s}$. We can conclude that diffusion did not have an important influence in the process of return to equilibrium but it is the interface phenomena that determine the kinetics of return to equilibrium. These phenomena may be due to a partial pressure jump at the interface which can be very important, reaching $2 \mathrm{kPa}$, but also to thermal phenomena. For this purpose, in the following section, we propose to calculate the temperature distribution in the vicinity of the interface in the solution in order to study the influence of temperature on the return to equilibrium.

\subsection{Influence of temperature at the liquid-gas interface on TCE vapor pressure}

Temperature variations in the vicinity of the interface are calculated using equation (26). Fig. 5 represents the temperature profiles of TCE as a function of diffusion length during time evolution. The figure shows that the drop in surface temperature is substantially equal to $0.013^{\circ} \mathrm{C}$. 


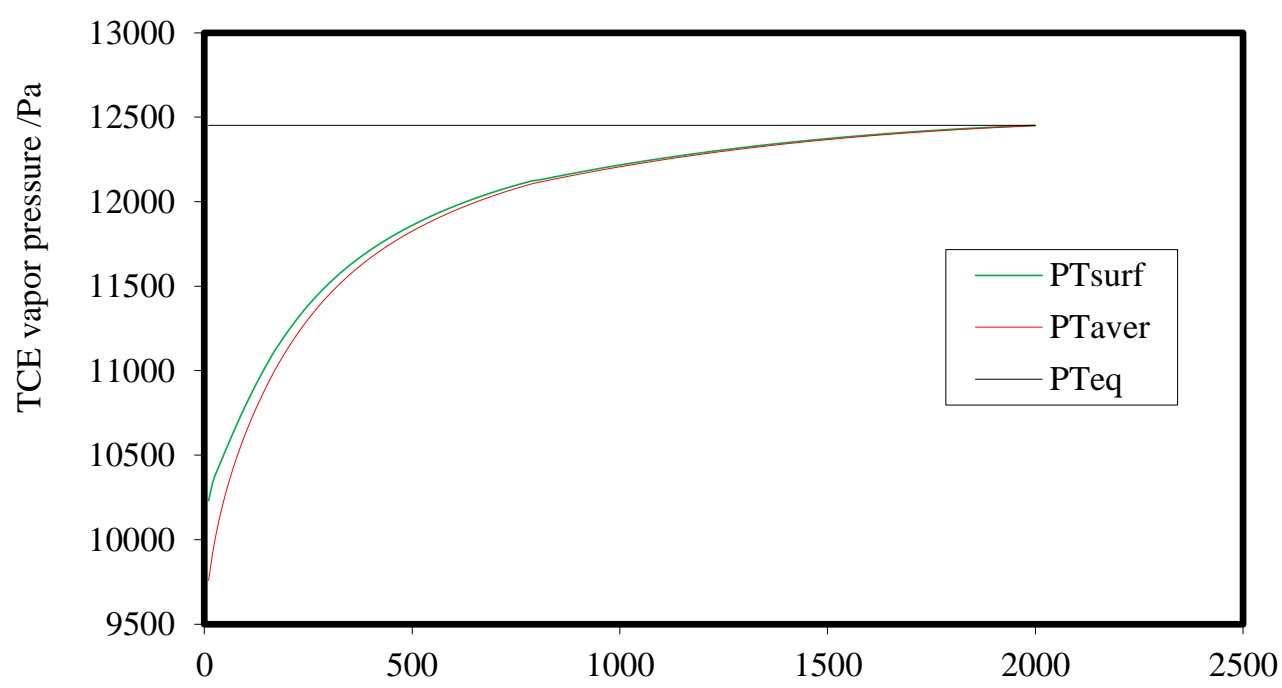

Time /s

Fig. 3 Variation of simulated vapor pressure, $P_{\mathrm{Tsur}}$, average partial vapor pressure measured by the pressure sensor, $P_{\text {Taver }}$ and the equilibrium partial pressure, $P_{\text {Teq }}$

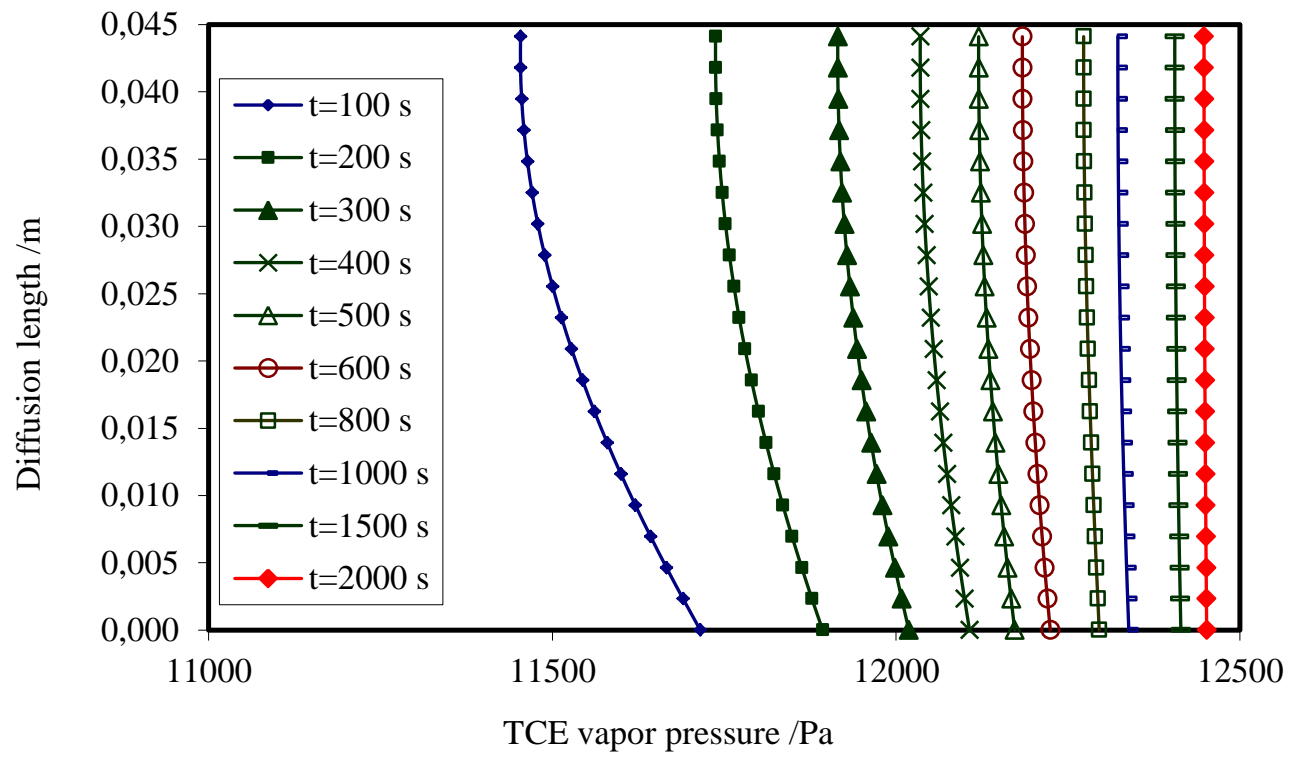

Fig. 4 Evolution of the profile of vapor pressure above the solution of TCE

This value does not take into account the contributions of surface heat by radiation or conduction through the metal parts of the device. However it constitutes an upper limit of the temperature drop and cannot significantly alter the equilibrium partial pressure of the liquid. It can therefore be assumed that the temperature along the diffusion length is almost constant and that its weak fluctuations do not significantly alter the equilibrium partial pressure of TCE or the kinetics of return to equilibrium.

\subsection{Determination of the evaporation coefficient of TCE}

\subsubsection{Influence of TCE content and pressure on the evaporation coefficient of TCE}

The evaporation coefficients for pure TCE at temperatures of $20{ }^{\circ} \mathrm{C}$ and $30{ }^{\circ} \mathrm{C}$ are respectively given by Fig. 6 and Fig. 7 for different pressures in the gaseous phase depending on TCE content in the soil. The curves show a 
similar shape to those obtained with water. For all these curves, it can be seen that the maximum value of evaporation coefficient is reached for about $1.5 \%$ of TCE content. For TCE contents lower than 1.5\%, hygroscopic effects related to the adsorption of the compound on the solid phase become important. Under these conditions, binding energy slows down the kinetics of evaporation. Above $1.5 \%$ of TCE content, it can be noted that the kinetics of evaporation also slow down. This new decrease may be due to a decrease in the interfacial surface liquid/gas which participates in the phase change of the TCE.

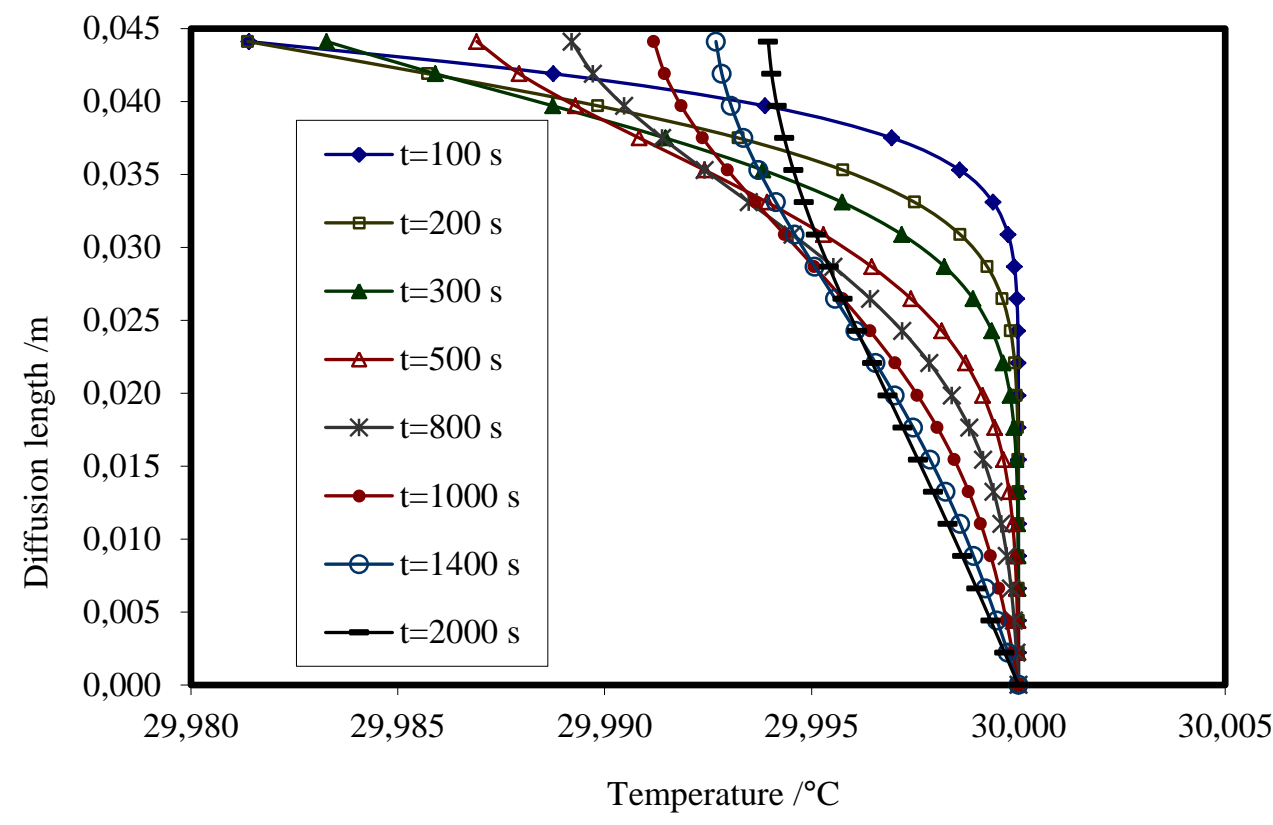

Fig. 5 Evolution of temperature profiles

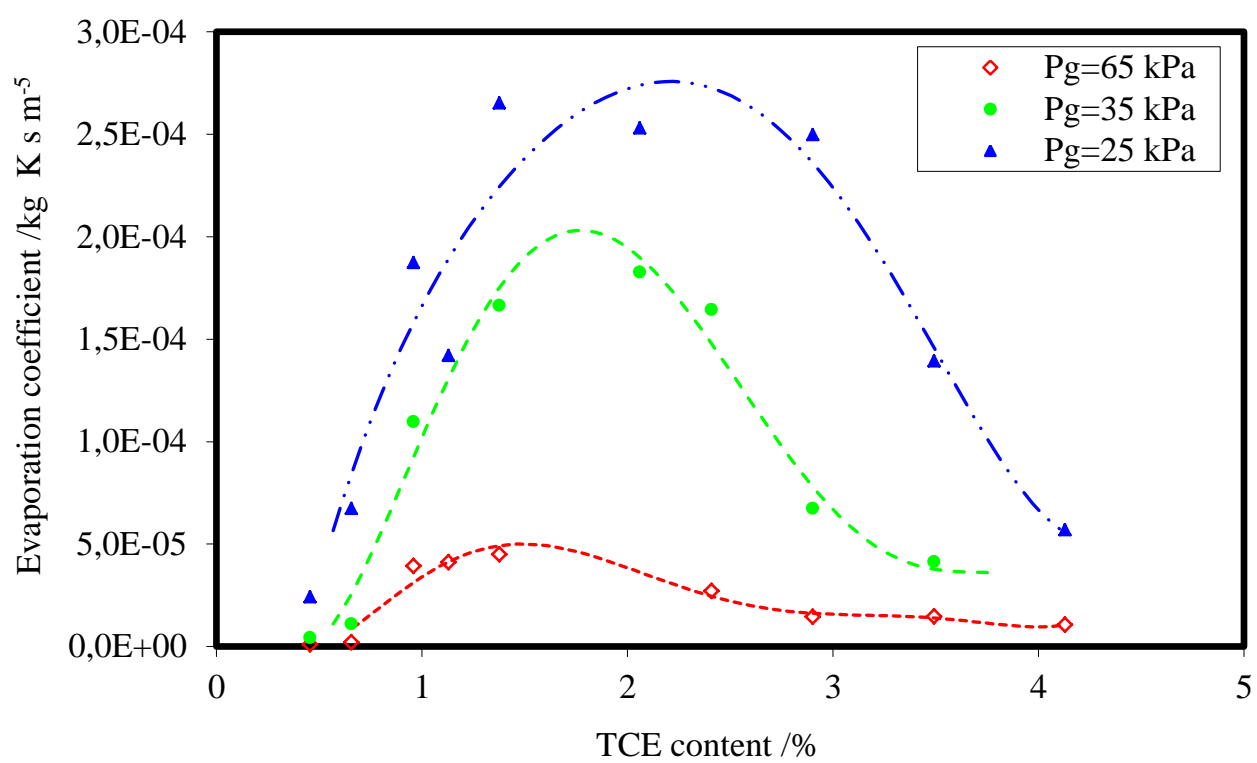

Fig. 6 Evaporation coefficient of TCE at different values of vapor pressures for $\mathrm{T}=20^{\circ} \mathrm{C}$

Also, one can see on Fig. 6 and Fig. 7 that the evaporation coefficient significantly decreases when the gas pressure increases for the three values studied i.e. $25 \mathrm{kPa}, 35 \mathrm{kPa}$ and $65 \mathrm{kPa}$. Previous studies conducted by Lozano et al. (2008) on water in soil showed that the evaporation coefficient of water increases with pressure. This difference in behavior is probably due to the high volatility of TCE whose saturated vapor pressure is about 3 times greater than that of water at $30{ }^{\circ} \mathrm{C}$. In comparison, the maximum TCE evaporation coefficient is obtained for $1.5 \%$ of TCE content. This represents $37.5 \%$ of the hygroscopic limit which is $4 \%$ of TCE content. However, 
the results of the evaporation coefficient obtained with water establish that the maximum is reached at the boundary of the hygroscopic domain i.e. about $7 \%$ of water content.

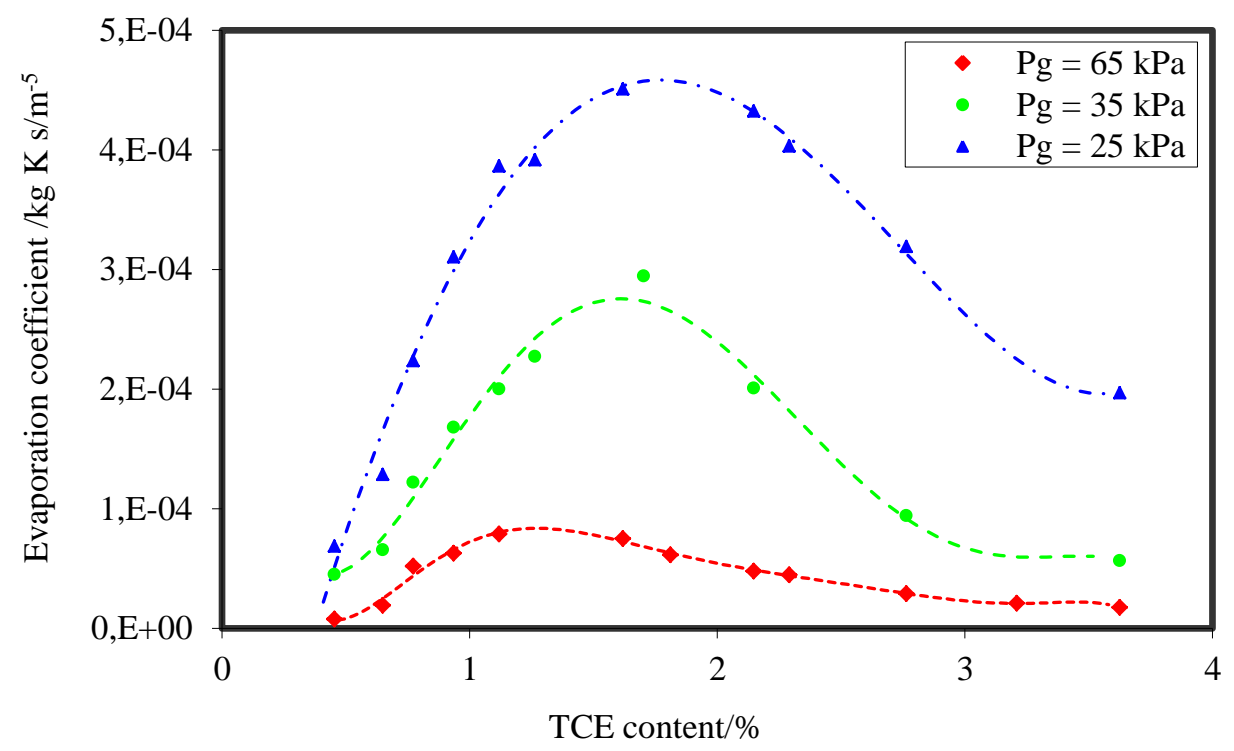

Fig. 7 Evaporation coefficient of TCE at different values of vapor pressures for $\mathrm{T}=30{ }^{\circ} \mathrm{C}$

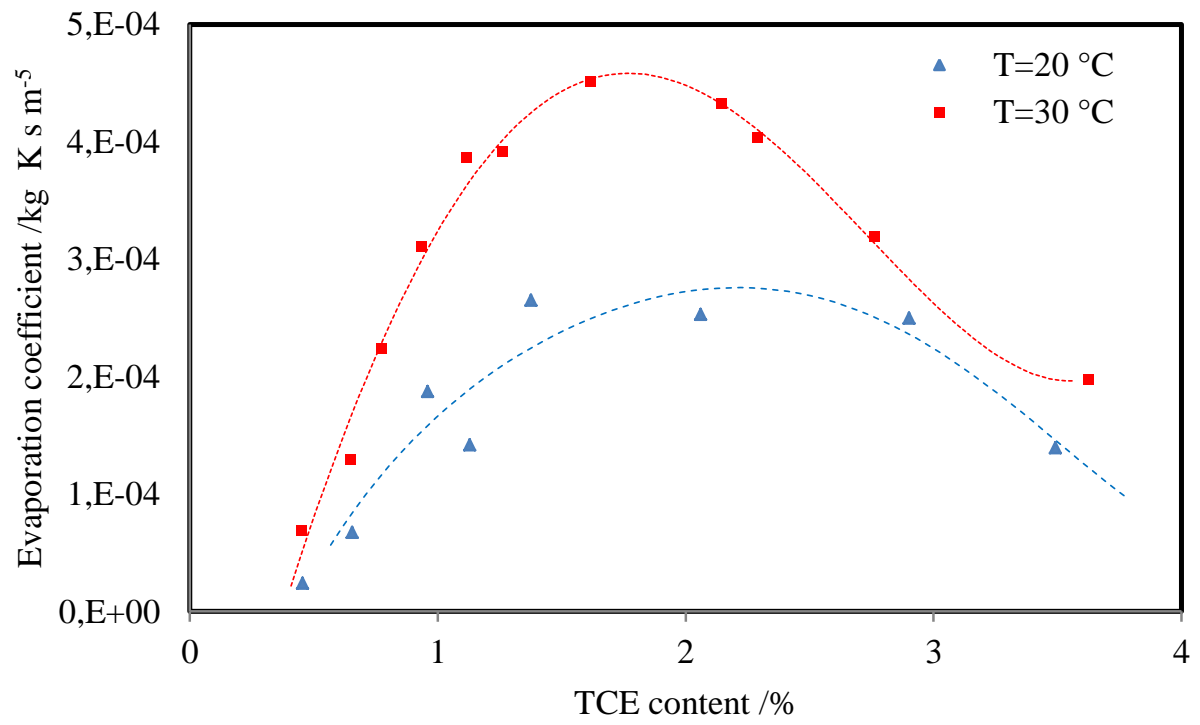

Fig. 8 Comparison of TCE evaporation coefficients at two different temperatures for $P_{\mathrm{g}}=25 \mathrm{kPa}$

\subsubsection{Influence of temperature on the evaporation coefficient of TCE}

To study the influence of temperature on the mechanisms of evaporation, we have superimposed onto Fig. 8 the evaporation coefficient of TEC at $25 \mathrm{kPa}$ for the two temperatures investigated. The results of this figure reveal a significant difference between the two curves. The difference is particularly marked for TCE contents ranging from $1 \%$ to $2.5 \%$ and shows that the evaporation coefficient of TCE is greater at $30{ }^{\circ} \mathrm{C}$ than that at $20{ }^{\circ} \mathrm{C}$; i.e., the evaporation coefficient of TCE increases with temperature. The two curves present the same shape and reach their maximum for TCE content of $1.5 \%$ as has been shown in previous sections. This value of $1.5 \%$ seems to be independent of temperature and pressure. The conclusions on the role of temperature in the evaporation coefficient are the same for the two other values of gaseous pressure i.e. $35 \mathrm{kPa}$ and $65 \mathrm{kPa}$. This influence of temperature has been also observed for water (Chammari et al. 2003; Lozano et al. 2008). 


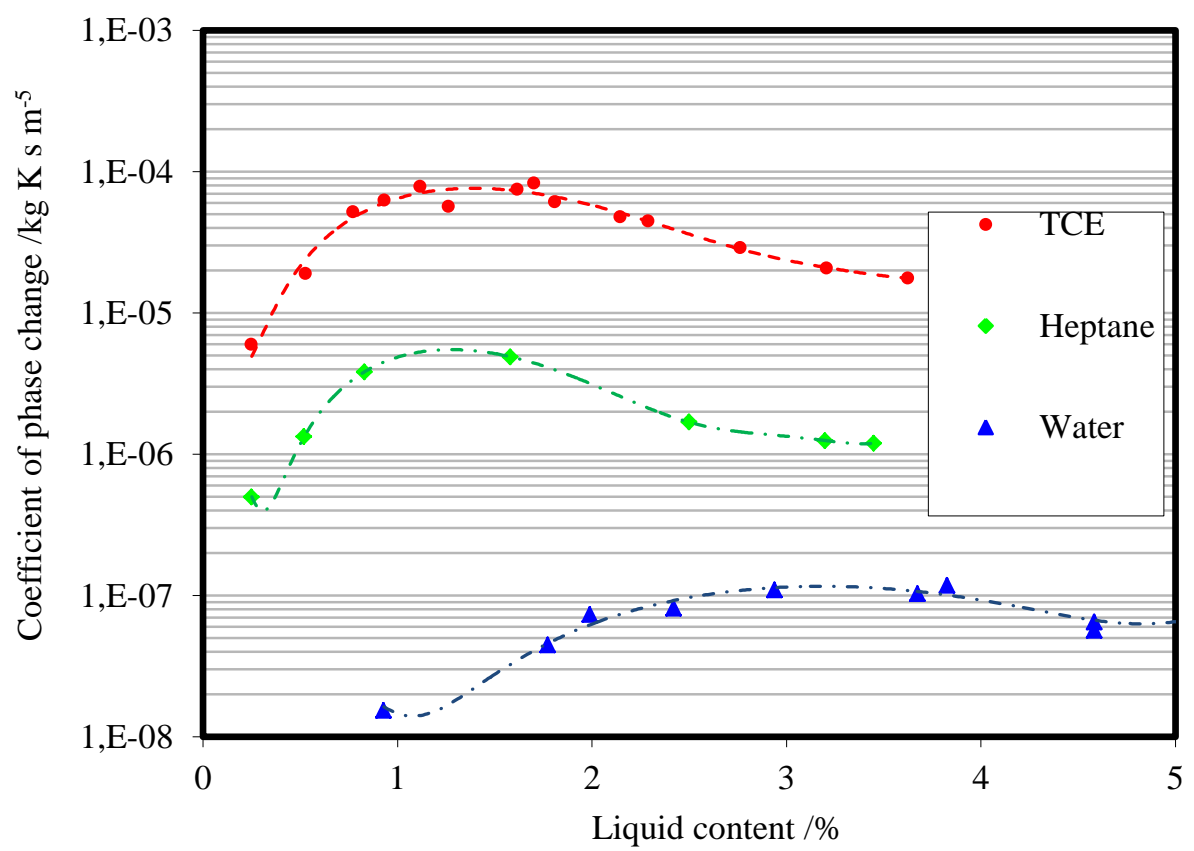

Fig. 9 Evaporation coefficients of water, heptane and TCE at $30{ }^{\circ} \mathrm{C}$ and $95 \mathrm{kPa}$

\subsubsection{Comparison of evaporation coefficients of water, heptane and TCE}

Fig. 9 gives the evaporation coefficients of water, heptane and TCE. To highlight the behavior of water compared with heptane and TCE, the linear scale of the vertical axis was transformed into a logarithmic scale. One can see that the evaporation coefficient of water presents the same shape but is lower than that of heptane and TCE. The evaporation coefficient of TCE is much greater than that of heptane and water. These results are related to the higher volatility of TCE compared to that of heptane and water. Indeed, it is well known that the more volatile the compound the greater, its saturated vapor pressure. According to data in the literature (Ouoba et al. 2010b), for the same temperature $P_{\text {weq }}<P_{\text {Heq }}<P_{\text {Teq }}$ which is in agreement with the results of Fig. 9.

\section{Conclusion}

This work has shown that it is possible to determine the evaporation coefficient of a volatile organic compound such as TCE and heptane by using an activity-meter, a new patented device (Bénet et al., 2012). Many tests were carried out using several values of TCE contents for different values of vapor pressure and temperature. This work highlights the weak influence of diffusion and surface temperature on TCE vapor pressure. The results show that the phenomenological approach adopted to quantify evaporation for water can be applied to TCE to highlight the more volatile nature of TCE compared to water and heptane. It appears from this study that the evaporation coefficient of TCE increases with temperature and decreases with the total pressure of the gas phase. As a result of the high volatility of TCE, it is difficult to conduct a large-scale experimental study on TCE evaporation in situ or on soil columns. Indeed, losses by volatilization during the preparation process of the sample can reach significant proportions and thus induce important errors in the final mass balance.

\section{Acknowledgments}

This work was done within the framework of collaboration between the University Montpellier 2, France and the University of Ouagadougou, Burkina-Faso and supported by the French Ministry of Foreign affairs. 


\section{References}

Altschuh J., Brüggemann R., Santl H., Eichinger G. and Piringer O.G.: Henry's Law Constant For A Diverse Set Of Organic Chemicals: Experimental Determination And Comparison Of Estimation Methods. Chemosphere 39, 1871-1887 (1999)

Auriault J.L. and Lewandowska J.: Effective diffusion coefficient: from homogenization to experiment. Transport in Porous Media 27, 205-223 (1997)

Bénet J.-C., Cousin B., Cherblanc F. and Ouoba S.: Device for measuring the activity of a liquid in a complex medium and associated method. United States Patent Application Publication, Pub. $\mathrm{n}^{\circ}$ US 20120266663A1 (Oct. 25, 2012)

Bénet J.-C., Lozano A.L., Cherblanc F. and Cousin B.: Phase Change of Water in a Hygroscopic Porous Medium. Phenomenological Relation and Experimental Analysis for Water in soil. Journal Non-Equilibrium Thermodynamic 34, 97-117 (2009)

Benker E., Davis G.B. and Barry D.A.: Estimating the retardation coefficient of trichloroethene for a sand aquifer low in sediment organic carbon - a comparison of methods. Journal of Contaminant Hydrology 30, 157 178 (1998)

Braida W. and Ong S.K.: Influence of Porous Media and Airflow Rate on the Fate of NAPLs Under Air Sparging. Transport in Porous Media 38, 29-42 (2000)

Brockbank S.A., Russon J.L., Giles N.F., Rowley R.L. and Wilding W.V.: Infinite dilution activity coefficients and Henry's law constants of compounds in water using the inert gas stripping method. Fluid Phase Equilibria $348,45-51(2013)$

Caron F., Manni G. and Workman W.J.G.: A large-scale laboratory experiment to determine the mass transfer of $\mathrm{CO}_{2}$ from a sandy soil to moving groundwater. Journal of Geochemical Exploration 64, 111-125 (1998)

Chammari A., Naon B., Cherblanc F. and Bénet J.-C. : Transfert d'eau en sol aride avec changement de phase. Comptes Rendus Mécanique 331, 759-765 (2003)

Dewulf J., Langenhove H.V. and Everaert P.: Determination of Henry's law coefficients by combination of the equilibrium partitioning in closed systems and solid-phase microextraction techniques. Journal of Chromatography A 830, 353-363 (1999)

Ficher U., Hinz C., Schulin R. and Stauffer F.: Assessment of nonequilibrium in gas-water mass transfer during advective gas-phase transport in soils. Journal of Contaminant Hydrology 33, 133-148 (1998)

Gerolymatou E., Vardoulakis I. and Hilfer R.: Simulating the saturation front using fractional diffusion model. In: Fifth GRACM International Congress on Computational Mechanics, Limassol (2005)

Hoeg S., Schöler H.F. and Warnatz J.: Assessment of interfacial mass transfer in water-unsaturated soils during vapour extraction. Journal of Contaminant Hydrology 74, 163-195 (2004)

Hornbuckle K.C., Jeremiason J.D., Sweet C.W. and Eisenreich S.J.: Seasonal Variations in Air-Water Exchange of Polychlorinated Biphenyls in Lake Superior. Environmental Science and Technology 28, 1491-1501 (1994)

Kish J.D., Leng C., Kelley J., Hiltner J., Zhang Y. and Liu Y.: An improved approach for measuring Henry's law coefficients of atmospheric organics. Atmospheric Environment 79, 561-565 (2013)

Lin T.-F., Little J.C. and Nazaroff W.W.: Transport and Sorption of Volatile Organic Compounds and Water Vapor within Dry Soil Grains. Environmental Science and Technology 28, 322-330 (1994)

Lincoff A.H. and Gossett J.M.: The determination of Henry's constant for volatile organics by equilibrium partitioning in closed systems. In: Brutsaert W, Jirka GH (ed) Gas Transfer at Water Surfaces, Reidel D Publishing,Bostonpp 17-25 (1984) 
Liu W., Shen S. and Riffat S.B.: Heat transfer and phase change of liquid in an inclined enclosure packed with unsaturated porous media. International Journal of Heat and Mass Transfer 45, 5209-5219 (2002)

Lozano A., Cherblanc F., Cousin B. and Bénet J.-C.: Experimental study and modeling of the water phase change kinetics in soils. European Journal of Soil Science 59, 939-949 (2008)

Ouedraogo F., Cherblanc F., Naon B. and Bénet J.-C.: Water transfer in soil at low water content. Is the local equilibrium assumption still appropriate? Journal of Hydrology 492, 117-127 (2013).

Ouoba S., Cousin B., Cherblanc F., J. Koulidiati and Bénet J.-C. : Une méthode mécanique pour déterminer la porosité totale d'un sol. Comptes Rendus Mécanique, DOI: 10.1016/j.crme.2014.07.003 (2014)

Ouoba S., Cousin B., Cherblanc F. and Bénet J.-C. : Une méthode mécanique pour mesurer la pression de vapeur d'équilibre de l'eau dans un milieu complexe. Comptes Rendus Mécanique 338, 113-119 (2010a)

Ouoba S., Cherblanc F., Cousin B. and Bénet J.-C.: A New Experimental Method to Determine the Sorption Isotherm of a Liquid in a Porous Medium. Environmental Science and Technology 44, 5915-5919 (2010b)

Rahli O., Topin F., Tadrist L. and Pantaloni J.: Analysis of heat transfer with liquid-vapor phase change in a forced-flow fluid moving through porous media. International Journal of Heat and Mass Transfer 39, 3959-3975 (1996)

Schreitmüller J. and Ballschmiter K.: Air-Water Equilibrium of Hexachlorocyclohexanes and Chloromethoxybenzenes in the North and South Atlantic. Environmental Science and Technology 29, 207-215 (1995)

Stadler L., Hinkelmann R. and Helmig R.: Modeling Macroporous Soils with a Two-Phase Dual-Permeability Model. Transport in Porous Media 95, 585-601 (2012)

Staudinger J. and Roberts P.V.: A Critical Review of Henry's Law Constants for Environmental Applications. Critical Reviews in Environmental Science and Technology 26, 205-297 (1996)

Staudinger J. and Roberts P.V.: A critical compilation of Henry's law constant temperature dependence relations for organic compounds in dilute aqueous solutions. Chemosphere 44, 561-576 (2001)

Steinberg S.M.: Sorption of Benzene and Triehioroethylene (TCE) on a Desert Soil: Effects of Moisture and Organic Matter. Chemosphere 33, 961-980 (1996)

Tong F., Niemi A., Yang Z., Fagerlund F., Licha T. and Sauter M.: A Numerical Model of Tracer Transport in a Non-isothermal Two-Phase Flow System for $\mathrm{CO}_{2}$ Geological Storage Characterization. Transport in Porous Media 98, 173-192. DOI 10.1007/s11242-013-0138-x (2013)

Unger D., Lam T., Schaefer C. and Kosson D.: Predicting the effect of moisture on vapor-phase sorption of volatile organic compounds to soils. Environmental Science and Technology 30, 1081-1091 (1996)

Zhao T.S., Cheng P. and Wang C.Y.: Buoyancy-induced flows and phase-change heat transfer in a vertical capillary structure with symmetric heating. Chemical Engineering Science 55, 2653-2661 (2000) 